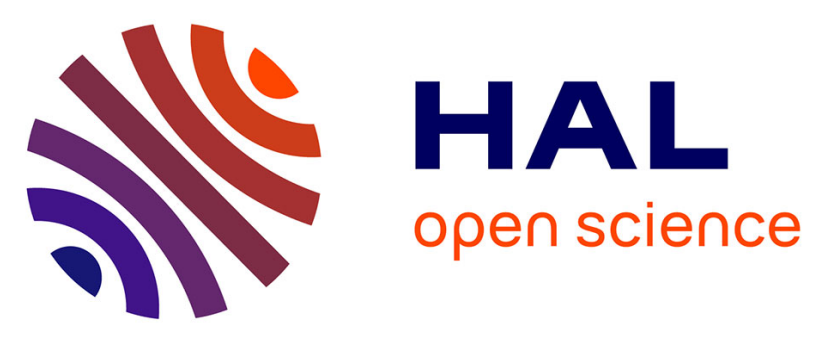

\title{
Cerebral aspergillosis: An emerging opportunistic infection in patients receiving ibrutinib for chronic lymphocytic leukemia?
}

E Gaye, Audrey Le Bot, Jean-Philippe Talarmin, Ronan Le Calloch, Sorya Belaz, Mathieu Dupont, Pierre Tattevin

\section{To cite this version:}

E Gaye, Audrey Le Bot, Jean-Philippe Talarmin, Ronan Le Calloch, Sorya Belaz, et al.. Cerebral aspergillosis: An emerging opportunistic infection in patients receiving ibrutinib for chronic lymphocytic leukemia?. Médecine et Maladies Infectieuses, 2018, 48 (4), pp.294-297. 10.1016/j.medmal.2018.01.003 . hal-01807746

HAL Id: hal-01807746

https://hal-univ-rennes1.archives-ouvertes.fr/hal-01807746

Submitted on 21 Jun 2018

HAL is a multi-disciplinary open access archive for the deposit and dissemination of scientific research documents, whether they are published or not. The documents may come from teaching and research institutions in France or abroad, or from public or private research centers.
L'archive ouverte pluridisciplinaire HAL, est destinée au dépôt et à la diffusion de documents scientifiques de niveau recherche, publiés ou non, émanant des établissements d'enseignement et de recherche français ou étrangers, des laboratoires publics ou privés. 
Cerebral aspergillosis: an emerging opportunistic infection in patients receiving ibrutinib for chronic lymphocytic leukemia?

Aspergillose cérébrale : une infection opportuniste émergente chez les patients traités par ibrutinib pour leucémie lymphoïde chronique?

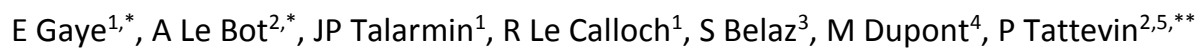

${ }^{1}$ Service de médecine interne, maladies du sang et infectiologie, CH Quimper, 29107 Quimper cedex, France

${ }^{2}$ Service des maladies infectieuses et réanimation médicale, CHU Pontchaillou, 35033 Rennes cedex, France

${ }^{3}$ Service de parasitologie-mycologie, CHU Pontchaillou, 35033 Rennes cedex, France

${ }^{4}$ Service des maladies respiratoires et infectieuses, $\mathrm{CH}$ Saint Malo, 35400 Saint Malo, France

${ }^{5}$ CIC-Inserm 0203, faculté de médecine, université Rennes 1, IFR140, 35000 Rennes, France

*These authors equally contributed to this work.

${ }^{* *}$ Corresponding author. Phone number: +33 298289564. Email address: pierre.tattevin@chu-rennes.fr

Mots clés : aspergillose cérébrale ; ibrutinib ; leucémie lymphoïde chronique

Keywords: chronic lymphocytic leukemia; ibrutinib; cerebral aspergillosis 


\section{Introduction}

Ibrutinib is a novel oral covalent inhibitor of Bruton's tyrosine kinase (BTK). It has been approved for the treatment of relapsing chronic lymphocytic leukemia (CLL), or CLL with high-risk cytogenetic abnormalities. Several cases of invasive aspergillosis have recently been reported in ibrutinib-treated patients. We report two cases of cerebral aspergillosis in CLL patients treated with ibrutinib.

\section{Case reports}

\section{First case patient}

A 75-year-old man was admitted for prolonged fever. He had been initiated on ibrutinib (280 mg daily) 12 days earlier, along with oral prednisone $(1 \mathrm{mg} / \mathrm{kg} / \mathrm{day})$ for relapsing CLL complicated by autoimmune hemolytic anemia (AIHA). Previous CLL treatments included obinutuzumab, chlorambucil, rituximab, and bendamustine. The physical examination performed upon admission was unremarkable, except for fever (body temperature $38^{\circ} \mathrm{C}$ ). The neutrophil count was $<0.1 \mathrm{G} / \mathrm{L}$, serum gamma globulins were $3.8 \mathrm{~g} / \mathrm{L}$. Chest computed tomography (CT) scan revealed bilateral nodules and enlarged mediastinal lymph nodes. Bronchoalveolar lavage (BAL) yielded Aspergillus fumigatus. Serum Aspergillus galactomannan antigen (enzymatic immuno-assay Platelia ${ }^{\circledR}$ Aspergillus Ag Bio-Rad, Marnes-la-Coquette, France) was 1.9 (index, normal values <0.5). The patient was treated with voriconazole $200 \mathrm{mg}$ BID after a loading dose. The dose was then gradually increased to $500 \mathrm{mg} \mathrm{BID}$, which allowed trough serum concentrations to reach the therapeutic target of $1-6 \mu \mathrm{g} / \mathrm{mL}$ throughout treatment. Filgrastim was introduced and ibrutinib was discontinued.

Three days later, while the neutrophil count was $>0.5 \mathrm{G} / \mathrm{L}$, the patient complained of visual impairment and ataxia. The brain MRI revealed several abscesses (Fig. 1). The cerebrospinal fluid (CSF) analysis was normal (no white cells, proteins $0.36 \mathrm{~g} / \mathrm{L}$ ), and no pathogen was identified on Gram staining, culture, and tests for galactomannan as well as Cryptococcus antigen. On Day 13 the 
patient presented with signs of intracranial hypertension with generalized seizure. The brain MRI revealed a significant increase in the abscess size. A stereotactic biopsy was performed: the histopathological examination confirmed the diagnosis of abscesses with septate hyphae compatible with Aspergillus sp., and positive Aspergillus PCR. Prednisone (40 mg/day) was added to voriconazole. The patient's condition gradually improved, and prednisone was gradually tapered until discontinuation on Day 60. On Day 180 the chest CT scan was normal, and the brain MRI revealed significant decrease in brain lesions. Voriconazole was discontinued. No sign indicative of aspergillosis relapse was observed during the 3-month follow-up after voriconazole discontinuation. Ibrutinib was not reintroduced.

\section{Second case patient}

A 65-year-old man was diagnosed with CLL, Binet stage C, with a high-risk cytogenetic abnormality of $17 \mathrm{p} 13$ deletion, complicated with AlHA non-responsive to corticosteroids. He was started on ibrutinib $\left(420 \mathrm{mg} /\right.$ day) associated with rituximab $\left(500 \mathrm{mg} / \mathrm{m}^{2}\right.$ every two weeks) and prednisone $(1.5 \mathrm{mg} / \mathrm{kg} / \mathrm{day})$. Two months later, the patient was admitted for acute dyspnea and cough. The physical examination was unremarkable. Laboratory tests revealed hemoglobin level of $8.9 \mathrm{~g} / \mathrm{dL}$ and neutrophil count of $7.1 \mathrm{G} / \mathrm{L}$. The chest CT scan revealed left pleural effusion and bilateral nodules (Fig. 2A). The direct examination of BAL revealed alveolar hemorrhage and mononuclear cell infiltrates. BAL, tracheal aspiration, and sputum culture all yielded Aspergillus fumigatus. Serum Aspergillus galactomannan antigen was 0.8 (index).

The patient was treated with oral voriconazole. Therapeutic drug monitoring was performed, with levels constantly $>1.5 \mu \mathrm{g} / \mathrm{mL}$ in the serum. Ibrutinib dosage was reduced to $140 \mathrm{mg} /$ day because of drug-drug interaction with voriconazole. Prednisone was reduced to $20 \mathrm{mg} /$ day and rituximab was discontinued. Cough and dyspnea gradually resolved over two weeks, and serum Aspergillus galactomannan antigen was $<0.5$ (index) at two months. 
One month later, while the patient was still receiving voriconazole therapy, he was admitted for light-headedness, balance disorder, and right hemiparesis. The brain MRI revealed multiple nodular lesions (Fig. 2B). The CSF analysis was normal, with no meningitis, normal protein and glucose values, and negative galactomannan antigen, $\beta$-D-glucan, and Aspergillus PCR. Voriconazole levels were within therapeutic targets (i.e., respectively 2.04 and $1.47 \mu \mathrm{g} / \mathrm{mL}$ in serum and CSF). The lung CT scan revealed significant decrease in pleural effusion and nodules, and galactomannan antigen in serum was $<0.5$ (index).

Voriconazole was associated with intravenous liposomal amphotericin B at $350 \mathrm{mg} /$ day. Neurologic signs resolved within 10 days. The brain MRI and chest CT scan were normal after three months of combination antifungal therapy, allowing discontinuation of liposomal amphotericin B. Voriconazole was discontinued after 12 months with good tolerability. The ibrutinib dose was increased to $420 \mathrm{mg} /$ day after voriconazole discontinuation. No sign indicative of aspergillosis relapse was observed during a 5-month follow-up after voriconazole discontinuation.

\section{Discussion}

Invasive aspergillosis is a fungal opportunistic infection mainly ascribed to neutrophil and macrophage phagocyte function deficiency, which enables the growth of Aspergillus spores and tissue invasion. The at-risk population has been well identified, including patients presenting with prolonged ( $>10$ days) and severe $(<0.5 \mathrm{G} / \mathrm{L})$ neutropenia, prolonged corticosteroid use, inherited severe immunodeficiency, or treatment with T cell immunosuppressants [1].

Ibrutinib is an oral covalent inhibitor of BTK, an enzyme produced by B-cell monocytes and macrophages that plays a role in down-regulating BCR and NF-KB signalling pathways in CLL cells and may also contribute to hypogammaglobulinemia [2]. The immunosuppression induced by ibrutinib inhibition of BTK may lead to an increased susceptibility to fungal infection. The two case patients reported herein presented with additional risk factors for invasive fungal infections, as they received prolonged corticosteroids or/and prior myelosuppressive therapies. Yet, they neither had prolonged 
neutropenia nor lymphopenia before and during BTK-inhibitor-therapy. This suggests the potential key role of ibrutinib as a predisposing factor for invasive aspergillosis in CLL patients.

Lung is the primary site of invasive aspergillosis; cerebral aspergillosis is rare [3]. Its clinical presentation is variable and nonspecific: meningitis, meningoencephalitis, seizures, or focal neurological signs related to abscesses. To date, nine cases of documented invasive aspergillosis have been reported in CLL patients receiving ibrutinib. Of note four of them (44\%) had cerebral aspergillosis [4,5] (Table 1). The additional two cases of cerebral aspergillosis reported herein are in line with those findings, and suggest that central nervous system may be a sanctuary site for invasive aspergillosis in CLL patients treated with ibrutinib. Accordingly, careful and repeated neurological examinations are required in patients presenting with invasive aspergillosis after ibrutinib treatment, with a very low threshold for prescribing brain MRI. Surprisingly, our second patient presented with neurological signs after three months of optimal treatment for invasive aspergillosis (voriconazole, with therapeutic drug monitoring).

Despite substantial improvements in invasive aspergillosis treatment [6], the mortality rate of cerebral aspergillosis remains high, with a 12-week overall mortality of more than $45 \%$ [3]. Recent guidelines of the infectious diseases society of America (IDSA) recommend primary treatment with voriconazole for CNS aspergillosis, because of its good CNS penetration. Combination with liposomal amphotericin B is used as salvage treatment. Our two patients developed pulmonary and CNS aspergillosis soon after ibrutinib was introduced. Both had favorable outcome with prolonged voriconazole treatment, associated with ibrutinib discontinuation, and resolution of neutropenia for the first patient; liposomal amphotericin B combination, and reduction of the ibrutinib dose for the second patient.

\section{Conclusion}

Impaired T-cell mediated immunity in CLL together with prolonged corticosteroids and BTK inhibition through ibrutinib may create a perfect storm for the development of invasive aspergillosis, 
with a special predisposition for cerebral aspergillosis. Careful clinical and biological monitoring for invasive aspergillosis should be performed in CLL patients treated with ibrutinib, with a low threshold for prescribing brain imaging.

\section{Contribution of authors}

A. Le Bot and E. Gaye wrote the article. J.-P. Talarmin, R. Le Calloch, S. Belaz, M. Dupont, and P. Tattevin critically revised the article. All authors read and approved the final version of the article.

Funding. The authors did not receive any specific funding for this case report.

Conflicts of interest. The authors report no conflict of interest.

Acknowledgments. We would like to thank Pr Gangneux J.P., Dr Lemaitre F., Dr Revest M., and Dr Poinot M. for their support. 


\section{REFERENCES}

1. De Pauw B, Walsh TJ, Donnelly JP, Stevens DA, Edwards JE, Calandra T, et al. Revised definitions of invasive fungal disease from the European Organization for Research and Treatment of Cancer/Invasive Fungal Infections Cooperative Group and the National Institute of Allergy and Infectious Diseases Mycoses Study Group (EORTC/MSG) Consensus Group. Clin Infect Dis 2008;46(12):1813-21.

2. Herman SEM, Mustafa RZ, Gyamfi JA, Pittaluga S, Chang S, Chang B, et al. Ibrutinib inhibits BCR and NF-KB signaling and reduces tumor proliferation in tissue-resident cells of patients with CLL. Blood 2014;123(21):3286-95.

3. Lortholary O, Gangneux J-P, Sitbon K, Lebeau B, de Monbrison F, Le Strat Y, et al. Epidemiological trends in invasive aspergillosis in France: the SAIF network (2005-2007). Clin Microbiol Infect 2011;17(12):1882-9.

4. Ruchlemer R, Ben Ami R, Lachish T. Ibrutinib for Chronic Lymphocytic Leukemia. N Engl J Med 2016;374(16):1593-4.

5. Baron M, Zini JM, Challan Belval T, Vignon M, Denis B, Alanio A, et al. Fungal infections in patients treated with ibrutinib: two unusual cases of invasive aspergillosis and cryptococcal meningoencephalitis. Leuk Lymphoma 2017;58(12):2981-2982.

6. Herbrecht R, Denning DW, Patterson TF, Bennett JE, Greene RE, Oestmann J-W, et al. Voriconazole versus amphotericin B for primary therapy of invasive aspergillosis. N Engl J Med 2002;347(6):408-15.

7. Byrd JC, Brown JR, O’Brien S, Barrientos JC, Kay NE, Reddy NM, et al. Ibrutinib versus ofatumumab in previously treated chronic lymphoid leukemia. N Engl J Med 2014;371(3):213-23. 
8. Jain $P$, Keating $M$, Wierda W, Estrov Z, Ferrajoli A, Jain N, et al. Outcomes of patients with chronic lymphocytic leukemia after discontinuing ibrutinib. Blood 2015;125(13):2062-7.

9. Kreiniz N, Bejar J, Polliack A, Tadmor T. Severe pneumonia associated with ibrutinib monotherapy for CLL and lymphoma. Hematol Oncol 2017 [Epub ahead of print]

10. Arthurs B, Wunderle K, Hsu M, Kim S. Invasive aspergillosis related to ibrutinib therapy for chronic lymphocytic leukemia. Respir Med Case Rep 2017;21:27-9. 
Figure 1. First case patient, coronal FLAIR-weighted cranial MRI on admission.

Figure 1. Coupe coronale de l'IRM cérébrale initiale du cas $n^{\circ} 1$, séquence FLAIR.

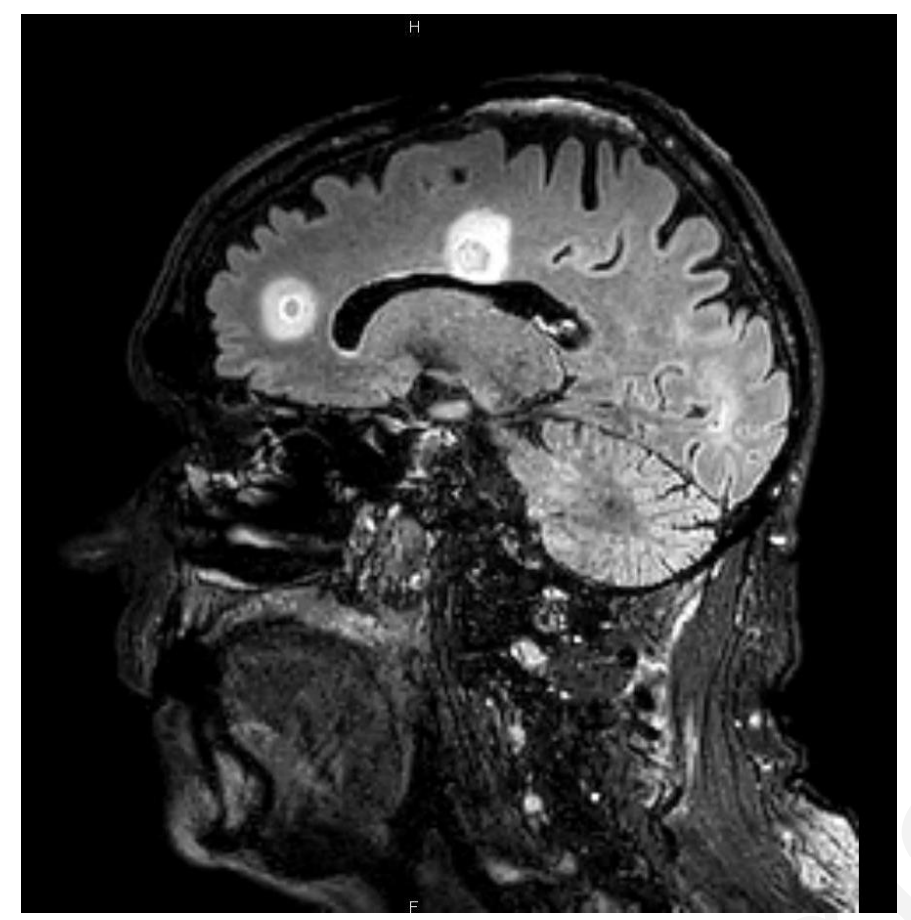


Figure 2A. Second case patient, chest CT scan. Bilateral nodules.

Figure 2A. TDM thoracique du cas $n^{\circ} 2$, nodules bilatéraux.

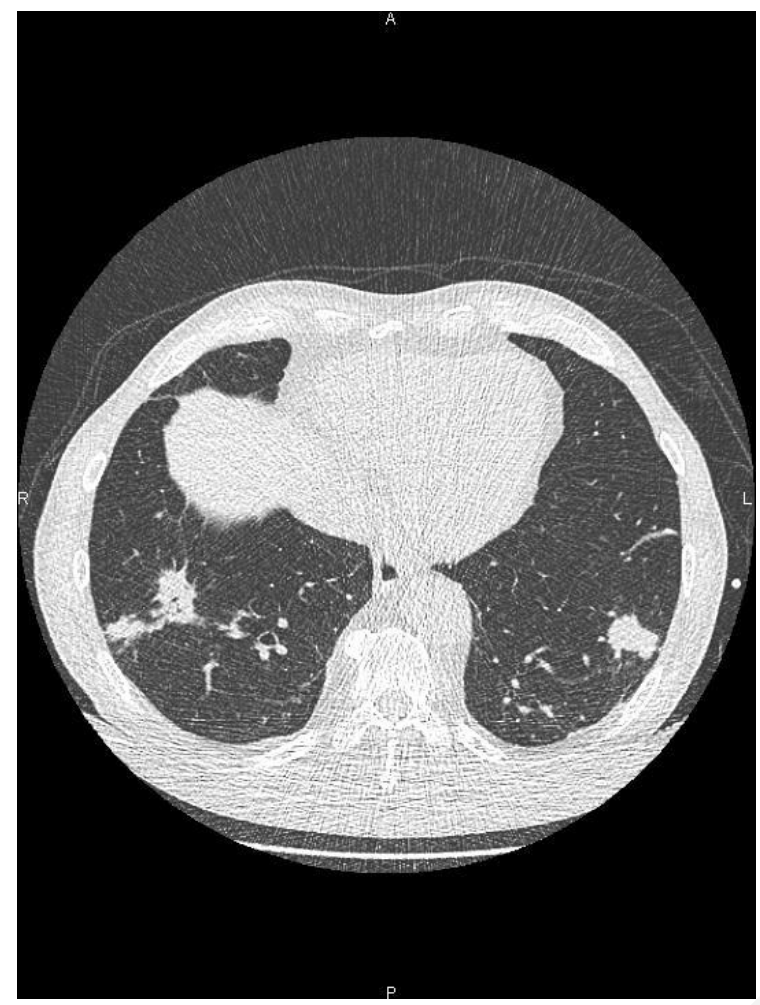

Figure 2B. Second case patient, transversal FLAIR-weighted cranial MRI on admission.

Figure 2B. Coupe transversale de l'IRM cérébrale initiale du cas $n^{\circ} 2$, séquence FLAIR.

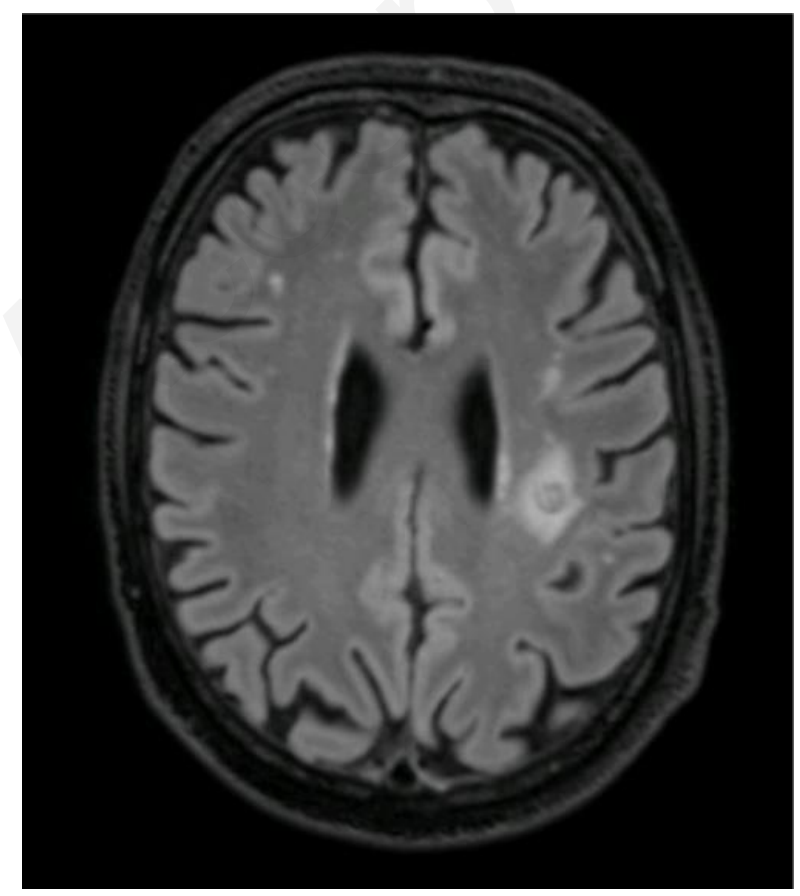


Table 1. Invasive aspergillosis in patients receiving ibrutinib : litterature review

\begin{tabular}{cccc}
\hline $\begin{array}{c}\text { Context, } \\
\text { reference }\end{array}$ & Description & Time from & Risk factors for invasive \\
ibrutinib start to & aspergillosis & Treatment, outcome \\
& aspergillosis & & \\
& diagnosis, months & &
\end{tabular}

\begin{tabular}{lc}
\hline $\begin{array}{l}\text { Phase } 3 \text { trial } \\
\text { [7] }\end{array}$ & $\begin{array}{c}\text { Two patients with pulmonary } \\
\text { aspergillosis }\end{array}$ \\
Phase 2 trial & Multifocal aspergillosis \\
[8]
\end{tabular}

[8]

Case report
[4]

[4]

aspergillosis $\mathrm{NC}$

Rituximab, fludarabin, corticosteroids

Corticosteroids

\section{Corticosteroids}

[9] mucormycosis
Neutropenia, rituximab,
fludarabin, corticosteroids

Neutropenia, rituximab,
fludarabin, corticosteroids neutropenia
Rituximab, fludarabin,
Case report Pulmonary aspergillosis.

[10]
- Patient 1 : voriconazole + amphotericin B, ibrutinib
discontinuation, died day 26

- Patient 2 : voriconazole + amphotericin B, ibrutinib discontinuation, cured (1 year follow-up)

- Patient 3 : amphotericin B, outcome NC

voriconazole, ibrutinib discontinuation, died

voriconazole + amphotericin B, ibrutininib discontinued, aspergillosis controlled

voriconazole, ibrutinib discontinuation, aspergillosis cured, but died 5 months later due to CLL 
Case report CNS and sinus aspergillosis

[5]

Case \#1

(reported

herein)

\section{Case \#2 \\ Pulmonary and CNS}

aspergillosis

$$
\text { aspergillosis }
$$

0.8

$\mathrm{NC}$

(reported

herein)
2

Corticosteroids voriconazole, ibrutinib discontinuation, sequels

voriconazole, ibrutinib discontinuation, aspergillosis cured

voriconazole + amphotericin $\mathrm{B}$, ibrutinib maintained, cured (1 year follow-up)

NC, not communicated; CNS, central nervous system; MRI, magnetic resonance imaging; CLL, chronic lymphocytic leukemia 